\title{
ANÁLISE ESPACIAL DOS CASOS DA COVID-19 E LEITOS DE TERAPIA INTENSIVA NO ESTADO DA BAHIA-BRASIL
}

\section{SPATIAL ANALYSIS OF COVID-19 CASES AND INTENSIVE CARE BEDS IN THE STATE OF BAHIA-BRAZIL}

\author{
Sarah Andrade Sampaio \\ Mestranda no Programa de Pós-Graduação em Estudos Territoriais (PROET) \\ Universidade do Estado da Bahia - UNEB - campus I \\ sarahandradegeo@gmail.com
}

Gabriel Carneiro Silva Cunha

Graduando do curso de Geografia Universidade Federal do Vale do São Francisco - UNIVASF - campus Senhor do Bonfim (BA) gabriel.carneiro@discente.univasf.edu.br

Felipe de Souza Reis

Graduando do curso de Geografia Universidade Federal do Vale do São Francisco - UNIVASF - campus Senhor do Bonfim (BA) felipesouzareis01@gmail.com

Sirius Oliveira Souza Docente do Programa de Pós-Graduação em Estudos Territoriais (PROET- UNEB- Campus I) Professor Adjunto da Universidade Federal do Vale do São Francisco -campus Senhor do Bonfim (BA) sirius.souza@univasf.edu.br

\begin{abstract}
RESUMO
O presente texto tem como objetivo analisar a distribuição espacial dos casos confirmados da COVID-19 no Estado da Bahia, entre o período de março a junho de 2020, ao passo que busca analisar a distribuição dos leitos de terapia intensiva e da população com idade superior a 60 anos, tendo em vista a possibilidade de alocação dos equipamentos de suporte à saúde intensiva com base nos padrões de disseminação da doença e na concentração de idosos. Para tal, a partir de dados dos Boletins Epidemiológicos da Secretaria de Saúde do Estado da Bahia (SESAB, 2020) e do Portal COVID (IBGE, 2020) foram utilizadas ferramentas de Sistema de Informação Geográfica, para qualificação e análise da distribuição espacial da COVID-19. Os resultados apontam que a dispersão do vírus no território estadual teve forte relação com os eixos rodoviários e aéreos de maior porte do estado. Desta forma, até junho de 2020, 93,52\% dos municípios do estado não detinham de leitos de UTI, além disso, ressalta-se a alta taxa de incidência para a Região Sul do estado e destaca-se a concentração dos leitos de UTIs na Região Metropolitana de Salvador, ao passo que os municípios com maiores concentrações de idosos se concentram no Centro Oeste do estado, em municípios pequenos, com redes de saúde frágeis, o que desperta a necessidade para o planejamento de ações em saúde. Ao final, este trabalho legitima-se ao reconhecer padrões espaciais de rotas de dispersão e fornecer relevantes informações para a compreensão e mitigação de danos relacionado a pandemia da COVID-19.
\end{abstract}

Palavras-chave: Bahia. Distribuição espacial. COVID-19.

\begin{abstract}
The present paper aims to analyze the spatial distribution of confirmed cases of COVID-19 in the State of Bahia, between the period of March, 2020 to June, 2020, while it searchs to analyze the critical care beds' distribution of and the population with higher age to 60 years, owing to the possibility of allocating equipment to support intensive health based on the patterns of disease spread and the concentration of the elderly. Therefore, using the data from the Epidemiological Bulletins of the Health Secretariat of the State of Bahia (SESAB, 2020) and the COVID Portal (IBGE, 2020), the tools of the Geographic Information System were used to qualify and analyze the distribution of COVID -19. The results show that the virus's dispersion in
\end{abstract}

Recebido em: $27 / 11 / 2020$

Aceito para publicação em: 14/02/2021.

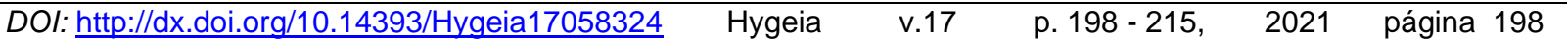


the territory's state had a strong relationship with the major road and air routes in the state. Thus, until June $2020,93.52 \%$ of the municipalities in the state did not have ICU beds, in addition, the high incidence rate for the Southern Region of the state is highlighted, concomitant with the concentration of ICU beds in the Metropolitan Region of Salvador, while the municipalities with the highest recommendations for the elderly are concentrated in the Midwest of the state, in small municipalities, with fragile health networks, which arouses the need for planning health actions. In the end, this work is legitimized by recognizing spatial patterns of dispersion routes and providing relevant information for understanding and mitigating damage related to the COVID-19's pandemic.

Keywords: Bahia. Spatial distribution. COVID-19.

\section{INTRODUÇÃO}

Segundo o Ministério da Saúde (BRASIL, 2020), os coronavírus (CoV) fazem parte de uma grande família viral (Coronaviridae), conhecida desde a década de 1960. Tal família é comum em diferentes espécies de animais e inabitualmente infecta pessoas. Neste contexto, desde dezembro de 2019 foi identificado em Wuhan na China a transmissão de um novo coronavírus (SARS-CoV-2) que ocasiona a doença COVID-19, a qual se disseminou para inúmeros países e continentes do globo terrestre, alçando a categoria de pandemia em 11 de março de 2020, caracterizando o pior dos cenários de uma epidemia, quando ela alcança níveis mundiais (REZENDE, 1998; BRASIL, 2020).

Neste âmbito, a disseminação do novo coronavírus se tornou um fenômeno de premente análise, visto sua magnitude e a distribuição espacial da COVID-19, uma doença que expressa uma perspectiva clínica oscilando de infecções assintomáticas, oligossintomáticas (pouco sintomas) a quadro graves.

No que tange à disseminação e complicações causadas pelo SARS-CoV-2, dados da Organização Mundial da Saúde (OMS) divulgados pela Organização Pan-Americana da Saúde (OPAS, 2020b) apontam que cerca de $80 \%$ dos pacientes podem apresentar características assintomáticas, o que dificulta ainda mais seu rastreio e análise, sendo que aproximadamente $15 \%$ dos infectados podem progredir para doença grave, requerendo atendimento hospitalar por exibirem insuficiência respiratória, ao passo que cerca de $5 \%$ dos infectados podem evoluir para o estado crítico, necessitando de suporte ventilatório e de Unidades de Terapia Intensiva (UTIs) (OPAS, 2020b).

Em virtude da característica assintomática e de sua alta capacidade de propagação, pesquisadores e autoridades temem que o número exponencial de pessoas contaminadas resulte em um colapso no sistema de saúde (BRASIL, 2020; CARDOSO et al., 2020). Neste contexto, Pedrosa e Albuquerque (2020) destacam a importância de estudos sobre a disponibilidade e distribuição dos leitos de UTI, enquanto unidades hospitalares essenciais ao tratamento dos pacientes em estado grave da COVID19 (BRASIL, 2020; RACHE et al., 2020).

Entre os infectados, sabe-se que pessoas com 60 anos ou mais e indivíduos que detêm condições de saúde preexistentes, como câncer, diabetes, doenças cardíacas, doenças pulmonares, ou hipertensão, correm maior risco de evoluírem para quadros críticos da doença (OPAS, 2020b). No caso da população idosa, foco deste trabalho, a OMS aponta maior grau de letalidade para este grupo (OPAS, 2020a). Barbosa et al. (2020) confirma este maior risco, ao relatar que dados sobre a propagação do MERS-CoV, coronavírus da Síndrome Respiratória do Oriente Médio e dados do coronavírus da Síndrome Respiratória Aguda Grave SARS-CoV, em ambos os casos, dentre os fatores de risco, o maior número de óbitos se concentrou na população idosa (BARBOSA et al., 2020).

Desta forma, tendo em vista essa população suscetível a maiores complicações e a elevada disseminação do vírus, tanto os gestores dos sistemas de saúde, quanto às comunidades acadêmicas voltaram-se à análise desta recente crise, na busca por alternativas viáveis para a contenção e mitigação da disseminação e também na procura pelo entendimento de sua distribuição espacial, com vistas a contribuir para o planejamento e gestão dos sistemas de saúde (DIAS et al., 2020; CARDOSO et al., 2020).

No Brasil, o primeiro paciente a testar positivo ao vírus foi registrado no dia 25 de fevereiro de 2020 em São Paulo, colocando o país como o primeiro da América Latina a reportar o SARS-CoV-2. Já no

DOI: http://dx.doi.org/10.14393/Hygeia17058324 Hygeia $\quad$ v.17 $\quad$ p. 198-215, 2021 página 199


Estado da Bahia, o primeiro caso confirmado data de 06 de março de 2020 (BRASIL, 2020; PEDROSA; ALBUQUERQUE, 2020). Desde então, pesquisadores de distintas instituições têm se debruçado sobre o número de contaminados e as possíveis análise espaciais relacionadas.

No que se refere à análise espacial, Câmara et al. (2000) afirmam que consiste no procedimento de verificação de padrões geoestatísticos por meio de uma base de dados geográficos, que explicita a maneira como as variáveis estão correlacionadas ao espaço. Na atualidade, a análise espacial tem se fortalecido nas ferramentas disponibilizadas pelos Sistemas de Informações Geográficas (SIG), que em razão da disponibilidade e baixo custo, permitem mapear, compreender e analisar uma grande variedade de fenômenos, com uma rapidez e precisão sem precedentes, potencializando e fortalecendo o planejamento e gestão em saúde.

Tanto o comportamento da pandemia dentro dos territórios, quanto os quadros emergenciais dos municípios são passíveis de análises espaciais. Estas contribuem ao ampliar as possibilidades de inferência sobre o fenômeno estudado, acentuando a relevância da reflexão sobre os fenômenos e processos espaciais. Neste intuito, a análise espacial corrobora aos processos de planejamento e gestão em saúde, disponibilizando informações importantes para a criação de planos e estratégias de mitigação e/ou à criação de políticas públicas (CAVALCANTE; ABREU, 2020).

Sob esse ponto de vista, a Geografia, por meio do geoprocessamento, assume papel relevante em meio à crise, subsidiando análises espaciais em tempo real nos sistemas de saúde, designando relações entre estes e a população de risco, proporcionando visibilidade a distintos recortes espaciais, auxiliando no diagnóstico da interiorização desta nova pandemia. Desta maneira, pode-se afirmar que a análise espacial oferece bastante suporte nesse momento de inúmeras incertezas (REN et al., 2020; CARDOSO et al., 2020).

É cogente mencionar pesquisas de autores como Ren et al. (2020), Murugesan (2020) e Laia et al. (2020), que realizaram contribuições relacionadas à crise do novo coronavírus a nível internacional, oferecendo dados imediatos acerca do desenvolvimento da pandemia e das primeiras características patológicas identificadas. Destaca-se também o trabalho de Kang et al. (2020) que realizou um estudo precursor sobre os padrões espaciais e temporais da pandemia do COVID-19 na China continental e destacou a contribuição dos sistemas de transporte para a disseminação do vírus, fato também indicado por Zhao et al. (2020).

No contexto brasileiro, Cavalcante e Abreu (2020) realizaram, em recente pesquisa, o mapeamento da ocorrência dos primeiros casos da COVID-19 no Município do Rio de Janeiro, evidenciando a taxa de incidência da doença nos principais bairros da cidade. Em tal estudo, Cavalcante e Abreu (2020) concluíram que o alto risco de infecção e morte por COVID-19 concentrava-se na zona sul do município. Semelhantemente, Pedrosa e Albuquerque (2020) realizaram análise espacial dos casos da COVID-19 e leitos de terapia intensiva no Estado do Ceará. O estudo apresentou que o coeficiente de detecção de casos no estado era de 33 casos por 100.000 habitantes, com maior taxa de ocorrência na região metropolitana da capital.

Considerando o exposto, torna-se evidente que os aspectos atuais da evolução tecnológica permitem abordagens espaciais que ampliam a capacidade analítica epidemiológica, bem como dão margem a uma discussão das hipóteses etiológicas na distribuição geográfica dos eventos. Atentando para tal potencialidade, esse trabalho legitima-se frente ao reduzido número de estudos que versem sobre a distribuição espacial do novo coronavírus no Estado da Bahia. Neste contexto, autores como Silva et al. (2020), apontaram risco para ocorrência de novos casos da COVID-19 em 304 municípios do Estado da Bahia para o mês de abril de 2020. Ao passo que Pedrosa e Albuquerque (2020) reforçam a assustadora disseminação do vírus em âmbito nacional e estadual e destacam a importância do acompanhamento espaço-temporal do SARS-CoV-2. Desse modo, este trabalho também se justifica frente às possibilidades de fundamentar projetos de planejamento em saúde, oriundos de diversos segmentos, com destaque para o Sistema Único de Saúde (SUS) (CORREIA et al. 2004; REZENDE et al. 2007; CAVALCANTE; ABREU, 2020).

Partindo do pressuposto de que a disseminação da COVID-19 em solo baiano não se dá de maneira homogênea, é que este trabalho busca entender a transmissão comunitária do vírus por meio do mapeamento de sua distribuição, estendendo à comunidade e, principalmente às autoridades de vigilância e aos grupos de risco, o padrão epidemiológico de casos da COVID-19 por meio da cartografia digital. Trata-se, portanto, de um estudo da interiorização da doença e suas consequências espaciais (PEDROSA; ALBUQUERQUE, 2020; CAVALCANTE; ABREU, 2020). 
Diante de tais constatações, este trabalho tem o objetivo de avaliar a distribuição espacial dos casos confirmados da COVID-19 no Estado da Bahia, averiguando sua distribuição e comportamento epidemiológico entre os meses de março e junho de 2020, ao passo que analisa a distribuição dos leitos de terapia intensiva e da população com idade superior a 60 anos, tendo em vista a possibilidade de alocação dos equipamentos de suporte à saúde intensiva com base nos padrões de disseminação da doença e na concentração de idosos.

\section{MATERIAIS E MÉTODOS}

\section{Caracterização da área}

Ao longo do território brasileiro, optou-se por estudar o Estado da Bahia (Figura 1), situado na Região Nordeste, onde ocupa uma área de $564.760,427 \mathrm{~km}^{2}$ e faz divisa com oito estados brasileiros, sendo eles Pernambuco e Piauí ao norte, Tocantins a oeste, Goiás a sudeste, Sergipe e Alagoas a nordeste e Minas Gerais e Espírito Santo ao sul (IBGE, 2019). A escolha da área de estudo justifica-se pela Bahia ter sido o primeiro Estado da Região Nordeste a ter casos confirmados da COVID-19.

Segundo o Instituto Brasileiro de Geografia e Estatística (IBGE) o Estado da Bahia tem população estimada de 14.873.064 de pessoas, com uma densidade demográfica de 24,82 hab/ $/ \mathrm{km}^{2}$, distribuídas ao longo dos 417 municípios, com destaque para a capital Salvador. O estado possui 27 territórios de identidade e 17 municípios com população acima de 100 mil habitantes (IBGE, 2019; SEI, 2018).

Figura 1 - Mapa de localização do Estado da Bahia, Brasil

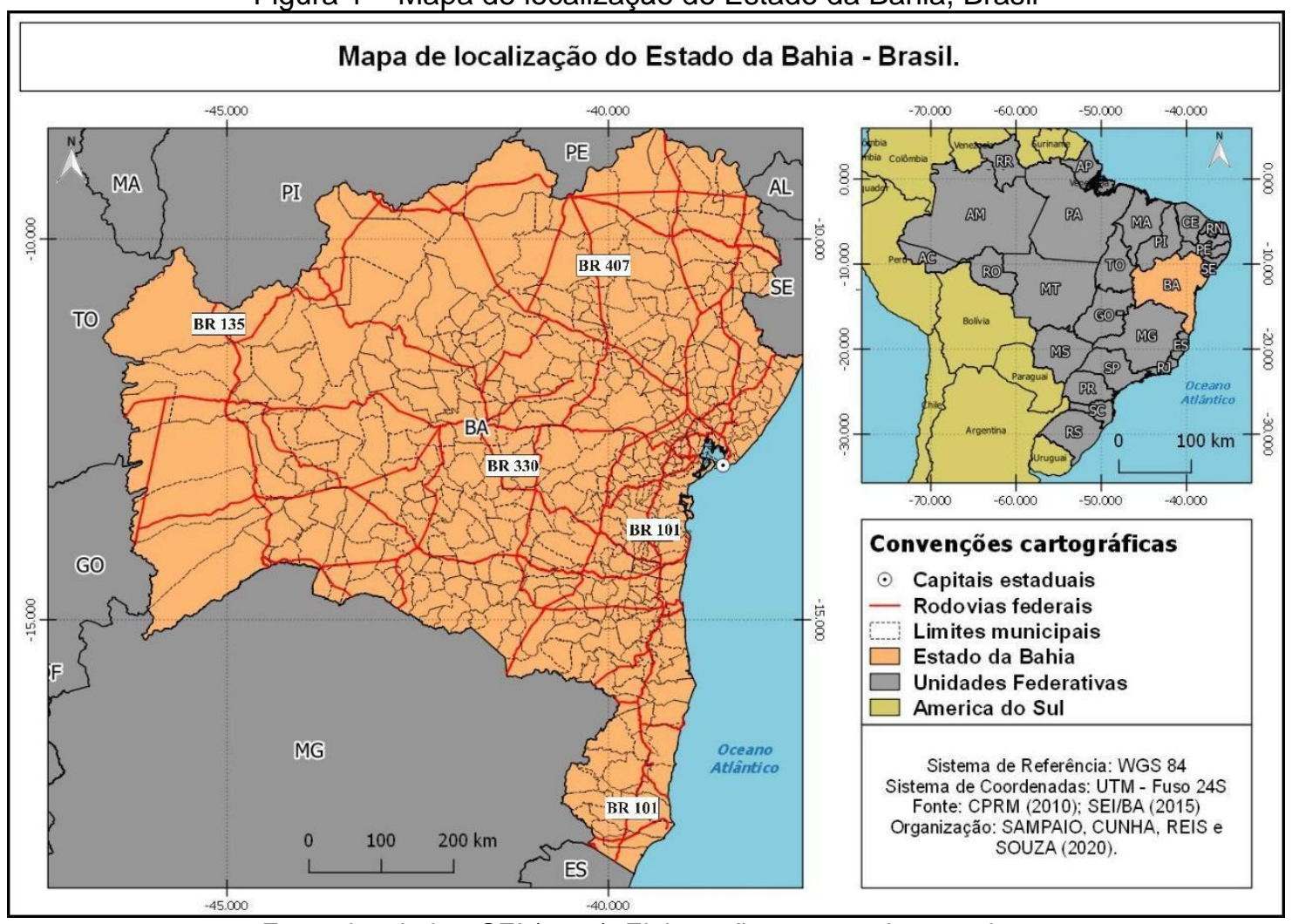

Fonte dos dados: SEI (2015). Elaboração: autores da pesquisa.

Quanto à estrutura econômica, segundo dados da Superintendência de Estudos Econômicos e Sociais da Bahia (SEI), em 2017 o estado ocupou o lugar de $7^{\text {a }}$ economia do Brasil, com um Produto Interno Bruto (PIB) avaliado em 268,7 bilhões de reais. Dados apontam incremento de $+0,3 \%$ no valor total no primeiro trimestre de 2020. Pode-se afirmar que os maiores setores da economia baiana são de comércios e serviços $(70,9 \%)$, indústria $(22,4 \%)$, e agropecuária $(6,7 \%)$, principalmente na região leste do estado. No setor de comércios e serviços, pode-se afirmar certa homogeneização em sua distribuição. Na indústria, destacam-se municípios como São Francisco do Conde, Camaçari, Feira de Santana e Eunápolis, ambos dispostos próximos da Rodovia Federal Mário Covas (BR-101) (SEI, 2017). 
No que tange à população, o estado apresenta o maior gradiente de concentração na zona leste do estado, sobretudo na Região Metropolitana de Salvador. Feira de Santana, Vitória da Conquista, Camaçari e, ao norte, Juazeiro também mostram grande percentual populacional. Contudo, a formação socioeconômica do estado é marcada por profunda desigualdade social, principalmente na distribuição da renda. Até mesmo a zona mais desenvolvida do estado, a região metropolitana da capital Salvador, ainda apresenta alto índice de segregação espacial e diferenciação monetária entre os grupos populacionais (GUERRA; GONZALEZ, 2013).

De acordo com Guerra e Teixeira (2000), a má distribuição de renda resulta da industrialização da década 1950 e se mostra de forma exógena e espasmódica, gerando grande desigualdade social. O estado baiano também apresenta certo grau de vulnerabilidade nos setores de planejamento em saúde. Dados do IBGE (2015), por exemplo, apontam grande percentual na taxa de mortalidade infantil. Outrossim, segundo o Ministério da Saúde, a Bahia enfrenta sérios problemas no combate ao Aedes Aegypti, reflexo do desordenamento no saneamento básico nos municípios, bem como dos problemas de planejamento de controle de vetores (SEI, 2017; GUERRA, 2018).

\section{Procedimentos Metodológicos}

Este trabalho fundamentou-se, inicialmente, em revisões bibliográficas sobre a evolução dos casos e óbitos da COVID-19 no Estado da Bahia. Em seguida, pela aquisição de arquivos vetoriais referentes ao objeto de estudo, além da integração dos dados obtidos em ambiente digital por meio do Sistema de Informações Geográficas (SIG) com uso do software QGIS $3.4^{\mathrm{TM}}$. Apresenta-se, a seguir, o detalhamento dos principais procedimentos executados em seus respectivos produtos cartográficos.

Iniciou-se a análise pela elaboração do Mapa de Evolução dos Casos da COVID-19 confirmados na área em estudo. Para este mapa foram obtidos, no portal da Secretaria de Saúde do Estado da Bahia (SESAB, 2020), dados referentes à quantidade de casos por município na Bahia nos quatro cenários escolhidos, são eles: 21 de março (15 dias após a confirmação do primeiro caso no Estado da Bahia), 21 de abril (um mês após o primeiro cenário), 21 de maio (dois meses após o primeiro cenário) e 21 de junho (três meses após o primeiro cenário) de 2020. Tais cenários foram escolhidos levando em conta a representatividade espacial e temporal da distribuição do vírus no estado ao longo do intervalo escolhido de três meses.

No que se refere à elaboração do Mapa de Densidade dos Casos Confirmados da COVID-19 no Estado da Bahia em 21 de junho de 2020, foram ponderadas as densidades em cada município com algum caso diagnosticado pelo vírus, aplicando o estimador de densidade de Kernel, de forma a identificar os padrões de concentração e distribuição da doença. Esse método tem como característica a execução de uma estatística de estimação de curvas de densidade, exposta por desenhos circulares nas imediações de cada ponto amostral (SOUZA et al 2013). Entre exemplos de pesquisas que analisaram as intensidades de doenças através do estimador de Kernel, pode-se citar Santos et al (2009) com enfoque na distribuição espacial da malária no Município de Juruena-MT; Barbosa et al (2013) cuja abordagem considerou aspectos acerca da tuberculose no Nordeste do Brasil; Souza et al. (2014) com pesquisas voltadas à distribuição espacial da hanseníase no Município de Juazeiro-BA; entre outros.

Como processo inicial para confecção deste mapa, foi criada uma malha de pontos, com a disposição de um ponto por município, sendo este representado por um valor atribuído ao número de casos confirmados (SESAB, 2020). Após a criação desta malha, aplicou-se o estimador de Kernel. Seguidamente, definindo a camada de pontos, delimitou-se o raio espacial de $50 \mathrm{~km}$ em relação ao valor atribuído ao ponto, originando um arquivo em formato raster. Em seguida, editou-se o número de classes, o gradiente de cores escolhidos e converteu-se o arquivo para a modalidade vetorial.

Para a organização do Mapa da Taxa de Incidência da COVID-19 no Estado da Bahia, foram obtidos dados referentes à taxa de incidência por município na Bahia na data de 21 de junho de 2020. Estes dados foram disponibilizados no boletim epidemiológico no 89, atualizado e publicado no portal da Secretaria de Saúde do Estado da Bahia (SESAB, 2020). De posse dos valores de incidência no formato de tabelas eletrônicas, estes foram importados para camadas vetoriais, seguidos pela organização da simbologia.

Segundo a Organização Pan-Americana da Saúde (OPAS, 2020a), a taxa de incidência pode ser definida como a quantidade de casos de uma determinada afecção de saúde dividida pela população exposta, num determinado local e período. Este indicador de nível de saúde possibilita revelar a probabilidade de um indivíduo ser afetado pela doença, bem como a falta de políticas públicas a fim

DOI: http://dx.doi.org/10.14393/Hygeia17058324 $\quad$ Hygeia $\quad$ v.17 $\quad$ p.198-215, 2021 página 202


de desenfrear o avanço de tal doença. Na realidade do estudo em questão, a taxa de incidência foi calculada a partir da quantidade de casos da COVID-19 em cada município baiano até o dia 21 de junho de 2020, e então realizada a divisão deste resultado com o número da população de cada município, multiplicando por 100.000, com intuito de atribuir um valor para cada 100.000 habitantes.

Dando sequência, elaborou-se com base nos dados disponíveis no Boletim epidemiológico no 89 da Secretaria de Saúde do Estado da Bahia (SESAB, 2020) o Mapa de Óbitos por COVID-19 no Estado da Bahia, por município de residência, até o dia 21 de junho de 2020. De posse dos dados, estes foram editados em planilhas eletrônicas, importados para as camadas vetoriais e organizados utilizando os comandos já indicados. Por se tratarem de valores absolutos, optou-se pela representação com base em círculos proporcionais, que de acordo com Archela e Théry (2008), consistem na expressão de dados pontuais caracterizados pela reprodução dimensional dos valores apresentados em relação a cada variável estabelecida. Estas representações se destacam ao apresentar uma variação no tamanho das formas correspondentes às quantidades expressas.

Posteriormente, organizou-se o mapa de distribuição de leitos de unidades de terapia intensiva e distribuição da população com 60 anos ou mais. Para este mapa, inicialmente procedeu-se a aquisição de dados da distribuição de leitos clínicos adultos e pediátricos de UTI nos municípios do Estado da Bahia. Tais informações foram obtidas gratuitamente no portal Geocombate COVID-19 BA referentes à distribuição de leitos por município até o mês de junho de 2020. Cabe acrescentar que esta plataforma é desenvolvida por um grupo de pesquisadores de diversas áreas da Universidade Federal da Bahia (UFBA), que tem como intuito apresentar informações espaciais acerca do enfrentamento da pandemia causada pela COVID-19 nos municípios baianos (GEOCOMBATE, 2020).

Já os dados referentes à distribuição da população com 60 anos ou mais no Estado da Bahia foram adquiridos em formato shapefile no recém lançado Portal COVID-19 do IBGE (2020), que reúne inúmeros dados, dentre eles os dados relativos ao percentual da população acima de 60 anos de idade por município do Brasil, obtidos a partir dos dados do Censo Demográfico de 2010 (IBGE, 2020). De posse de ambos os dados, estes foram unidos no software QGIS e procedeu-se a construção da simbologia dos mesmos. Para os valores percentuais, optou-se pela utilização de cores graduadas em um intervalo igual de 5 classes. Para os valores absolutos (leitos de UTI) optouse pela utilização de círculos proporcionais, distinguidos por variáveis em razão do tamanho, reproduzindo assim, a localização pontual de ocorrência, bem como a intensidade da representação. Ambas simbologias foram organizadas no comando propriedades do arquivo - simbologia. Vale ressaltar a limitação do estudo frente a utilização de dados do Censo Demográfico de 2010, entretanto, na inexistência de dados mais atualizados, estes tem sido amplamente utilizados por estudiosos do tema (MAGALHÃES et al., 2020; SIMIONATTO; BARBOSA; MARCHIORO, 2020; MATSUMOTO et al., 2020)

Cabe mencionar que a variável de pessoas com 60 anos ou mais foi selecionada tendo em vista que tal faixa etária compreende pessoas com "risco alto de desenvolver doença grave e morte após o desenvolvimento da doença" (BARBOSA et al, 2020, p. 9), evidenciando a necessidade do cuidado e acompanhamento específico da pessoa idosa, justificando também a relação proposta nesse momento com a distribuição dos leitos de Unidade de Terapia Intensiva no Estado da Bahia. Além disso, ressalta-se que tais variáveis foram consideradas como uma das perspectivas de análise demográfica, dentre tantas possíveis, a exemplo das variáveis de raça/cor, características econômicas, sanitárias e sociais, entre outras.

\section{RESULTADOS E DISCUSSÕES}

Em relação à evolução dos casos da COVID-19 no primeiro cenário analisado, conforme ilustrado na Figura 2, em 21 de março de 2020 o Estado da Bahia apresentava apenas sete municípios com casos confirmados, Salvador (23), Feira de Santana (6), Porto Seguro (5), Lauro de Freitas (3), Prado (2), Itabuna (1) e Camaçari (1), somando quarenta e um casos confirmados (SESAB, 2020). Amparando esta análise, Aguiar (2020) ressalta a influência dos aeroportos enquanto estruturas fixas que desencadeiam fluxos e conflitos na pandemia, os quais foram as principais portas de entrada do coronavírus, tendo em vista o fluxo de passageiros internacionais que posteriormente foram diagnosticados dentro do território nacional. Neste contexto, evidencia-se que dos sete municípios supracitados, dois apresentam aeroportos com voos internacionais e os outros cinco municípios distam no máximo $200 \mathrm{~km}$ de aeroportos regionais/nacionais.

DOI: http://dx.doi.org/10.14393/Hygeia17058324 $\quad$ Hygeia $\quad$ v.17 $\quad$ p. 198-215, 2021 página 203


Ainda sobre a influência dos aeroportos na dispersão da contaminação do Estado da Bahia, cabe ressaltar que o primeiro caso confirmado no estado, e por consequência na Região Nordeste, foi de uma mulher de Feira de Santana (a $109 \mathrm{~km}$ de Salvador) que esteve em Milão, retornou ao Brasil em 25 de fevereiro e teve sua contaminação oficializada em 06 de março, quando o Brasil detinha apenas nove casos em outros cinco estados. Em sequência, com base nos dados da Secretaria de Saúde do Estado da Bahia (SESAB, 2020), em 21 de abril de 2020, noventa e nove municípios do estado já apresentavam casos confirmados (Figura 2), ou seja, um aumento de cerca de $1.300 \%$ em comparação ao primeiro cenário. Dentre os municípios com casos confirmados, Salvador continuava com a maior proporção $(61,30 \%)$, seguido por Ilhéus $(6,12 \%)$, Feira de Santana $(4,06 \%)$ e Itabuna $(3,86 \%)$.

Em 21 de maio, conforme exposto nas Figuras 2 e 3, duzentos e vinte municípios do Estado da Bahia já apresentavam casos confirmados, resultando em um aumento de $120 \%$ em relação ao cenário anterior. Salvador continua com a maior proporção de casos contaminados $(64,61 \%)$, seguido de Itabuna $(6,32 \%)$, Ilhéus (3,93 \%), Feira de Santana (2,26\%), Jequié $(2,03 \%)$, dentre outros (SESAB, 2020). No quarto e último cenário analisado nesta pesquisa (21 de junho), o Estado da Bahia possuía o total de 46.279 de casos confirmados, distribuídos ao longo de 359 municípios. Considerando a distribuição dos casos confirmados neste cenário, a capital baiana perdura na concentração do maior número de casos (51,06\%), apesar de indicar uma redução de $13,55 \%$ em relação ao mês anterior, dado já associado às medidas de restrição adotadas pelos gestores municipais e estaduais.

Figura 2 - Mapa de Evolução dos casos da COVID-19 confirmados no Estado da Bahia

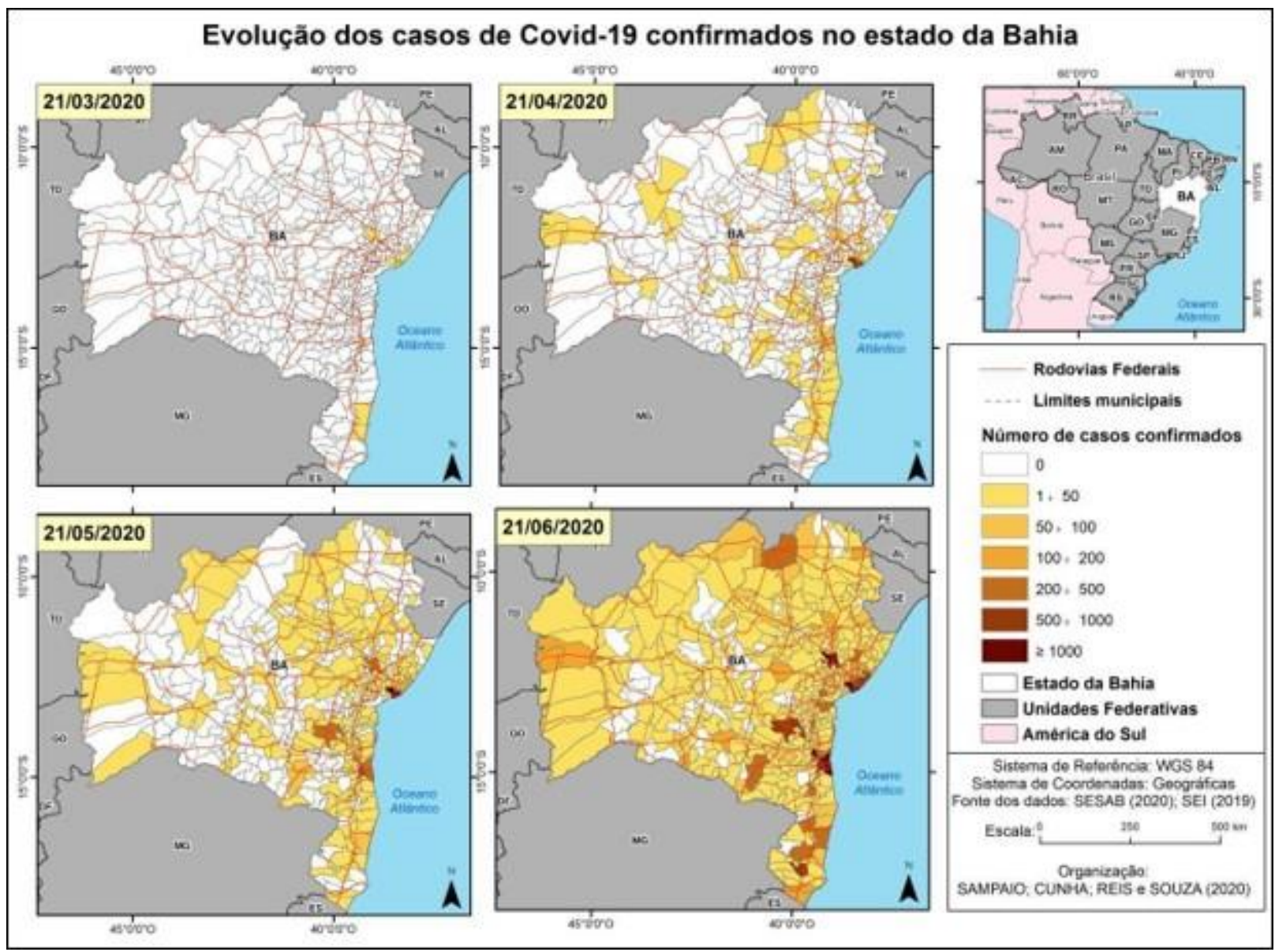

Fonte dos dados: SESAB (2020). Elaboração: autores da pesquisa.

Cabe mencionar que tais medidas de restrição foram adotadas de forma heterogênea no território estadual. Em suma, alguns municípios assumiram medidas mais rígidas antes mesmo do aparecimento de casos da COVID-19, enquanto outros mantiveram medidas com uma maior flexibilidade diante de um aumento expressivo no número de casos. Entre as medidas adotadas, pelo governo da Bahia e aplicados a todos os municípios, cita-se a suspensão de voos da Bahia para os 
Estados do Rio de Janeiro e São Paulo no dia 18 de março; a suspensão do transporte intermunicipal pela primeira vez no dia 20 de março, por um período de 10 dias, o qual foi prorrogado diversas vezes, e somente retomado parcialmente no mês de agosto; a suspensão de aulas nas escolas estaduais e da rede privada, a partir de 19 de março, cujo o retorno está sob responsabilidade das prefeituras municipais desde o mês de agosto; além da medida de suspensão de eventos que reúnam mais de 50 pessoas, a partir do dia 19 de março, a qual também foi flexibilizada a partir do mês de agosto e administrada pelos municípios; entre outros (G1, 2020).

Em 21 de junho, o Município de Itabuna ultrapassou Feira de Santana em proporção de casos confirmados, chegando a 3,80\%, ao passo que Feira de Santana chega a 2,96\%. Estes são seguidos por Lauro de Freitas, na região metropolitana da capital, com 2,16\% e Teixeira de Freitas, no extremo sul, com alarmantes $1,84 \%$, dentre outros (SESAB, 2020). Tais dados indicam o processo de interiorização do vírus com destaque para aeroportos e rodovias, enquanto meios preferenciais de transmissão e concentração do vírus, fato já evidenciado por outros autores em outros estados (MARTINUCl et al., 2020; AGUIAR, 2020).

Figura 3 - Evolução dos casos e óbitos da COVID-19 no Estado da Bahia, até o dia $21 / 06 / 2020$

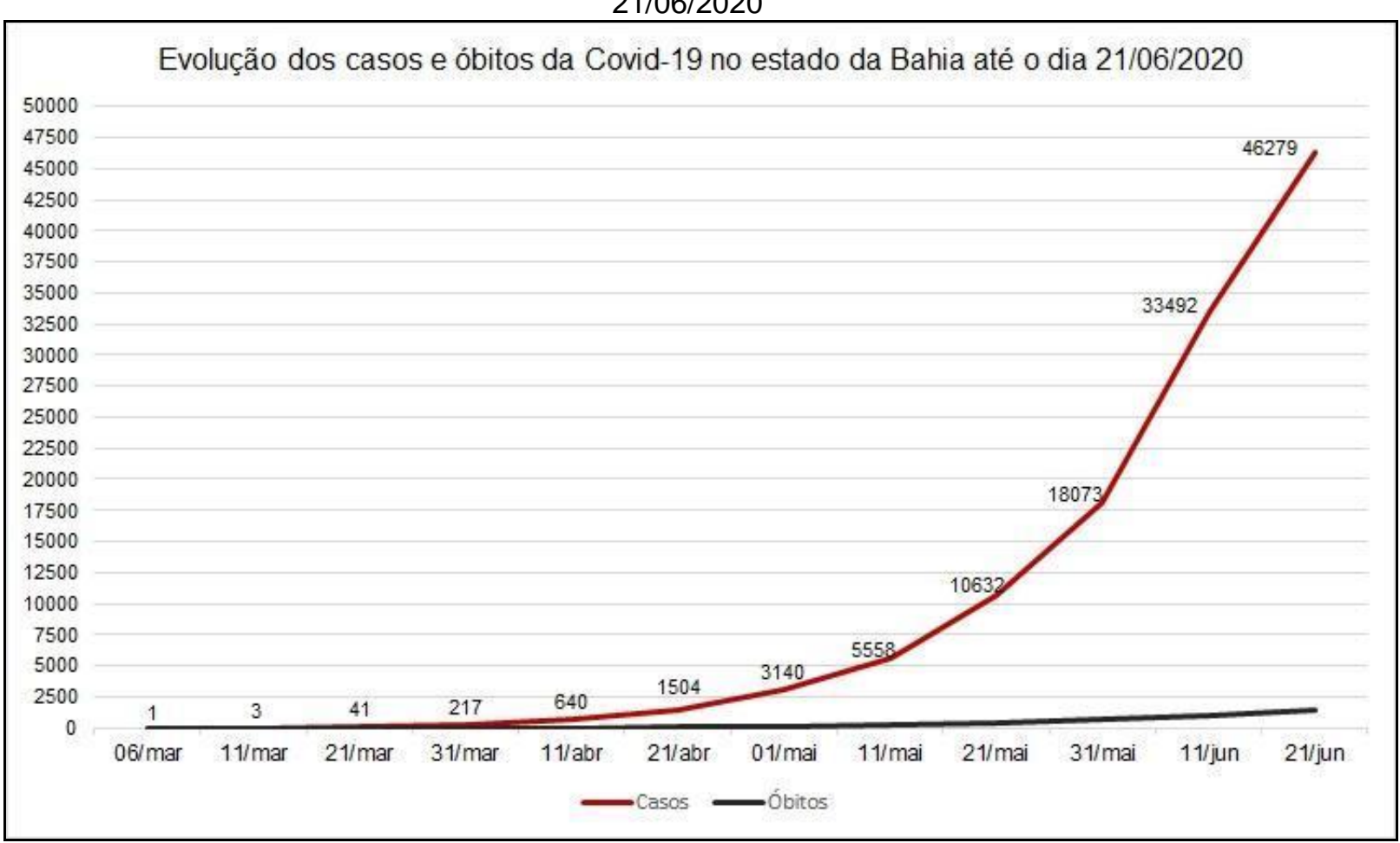

Fonte dos dados: SESAB (2020). Elaboração: autores da pesquisa.

No contexto da concentração dos casos confirmados, com base nos dados disponibilizados pela Secretaria de Saúde do Estado da Bahia (SESAB, 2020) foi elaborado o mapa de densidade dos casos confirmados da COVID-19 no último cenário estudado. Sobre a densidade de Kernel, Câmara e Carvalho (2004) observam que este método permite aferir a probabilidade de ocorrência de um determinado fenômeno estudado em cada célula de uma grade regular.

Desta forma, conforme exposto na Figura 4, o estimador Kernel dos números absolutos de casos confirmados em 21 de junho de 2020 indica a densidade muito alta em cerca de dez municípios localizados na Região Metropolitana de Salvador. Já outros treze municípios apresentam densidade alta, com destaque para os municípios de Feira de Santana, Itabuna, Ilhéus e Jequié. Cerca de cinquenta e um municípios apresentaram densidade média, dispostos principalmente no trecho leste do estado, com destaque para o sul e extremo sul, ao passo que sessenta e oito municípios apresentam densidade baixa, representados por alguns círculos espalhados pela região centro norte, centro e centro sul do estado. Seguidos pelos municípios que apresentavam baixa densidade, que neste cenário somavam cerca de duzentos e quarenta e cinco municípios.

Da mesma forma que na espacialização dos casos confirmados, a densidade de Kerne/ gerada atesta que a dispersão do vírus pelo território baiano se dá pelos eixos principais de transporte do estado, DOI: http://dx.doi.org/10.14393/Hygeia17058324 Hygeia v.17 $\quad$ p. 198-215, 2021 página 205 
sejam eles rodoviários, aéreos e/ou portuários. Desta forma, as regiões nordeste, leste, sul e extremo sul da Bahia apresentam maior densidade de casos confirmados, em razão da dialética concentração populacional e convergência de serviços e atividades econômicas, que em razão da pandemia, possibilitaram uma maior dispersão e contágio. Fato também relatado por autores em outros estados (MARTINUCl et al., 2020; SILVA et al., 2020; TEIXEIRA; SOUZA, 2020).

Figura 4 - Mapa de densidade dos casos confirmados da COVID-19 no Estado da Bahia, em $21 / 06 / 2020$

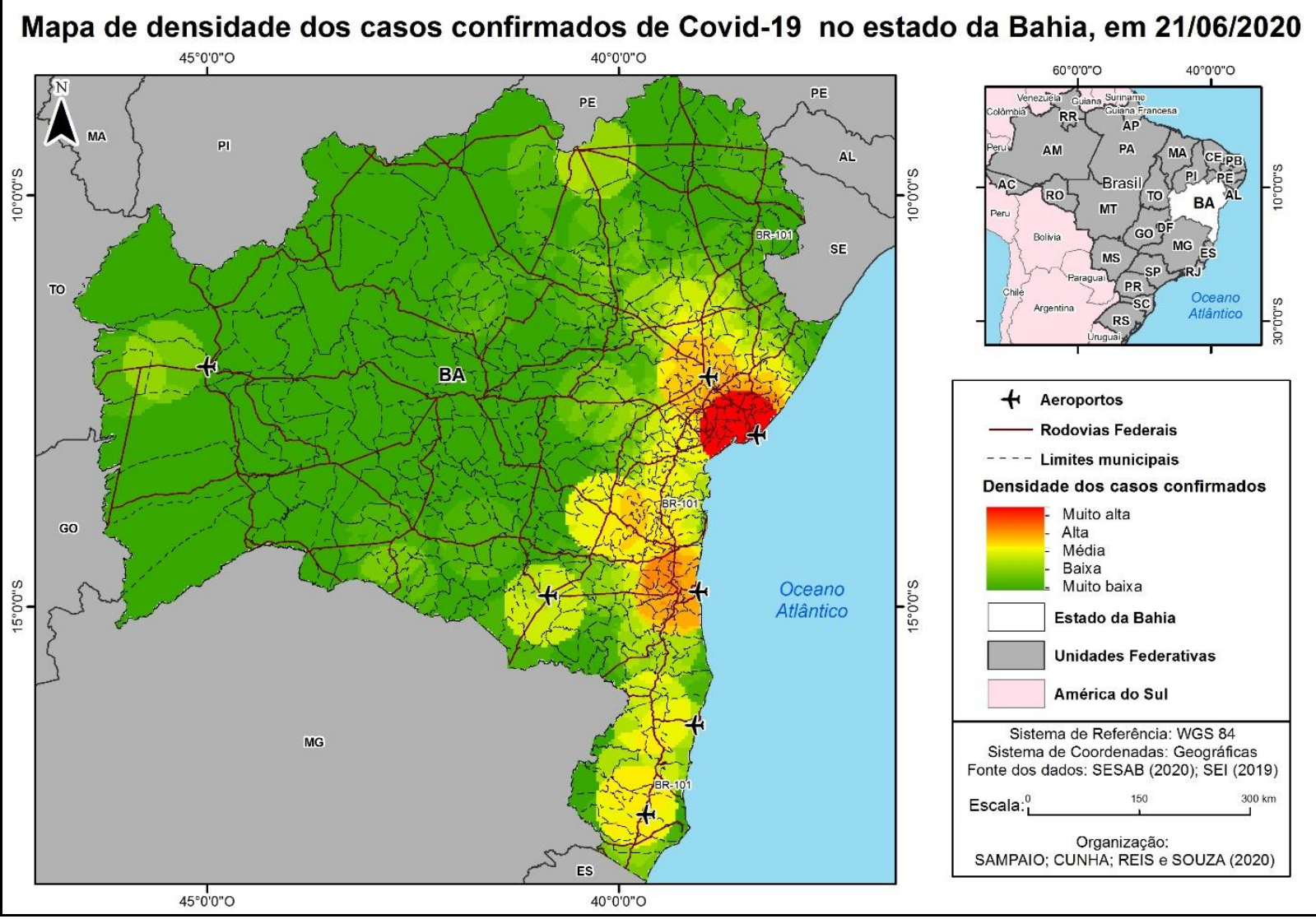

Fonte dos dados: SESAB (2020). Elaboração: autores da pesquisa.

No mesmo sentido, a fim de ampliar a compreensão da distribuição da doença e suas relações com a população nos municípios baianos, evidencia-se a necessidade de análise sobre a incidência da COVID-19, com destaque para os municípios situados ao longo da rodovia federal BR-101, um grande eixo de fluxo de pessoas e mercadorias no estado, e por consequência do vírus.

Assim, quanto à incidência da COVID-19 no Estado da Bahia, elaborou-se o mapa exposto na Figura 5, com base na taxa de incidência da COVID-19 em 21 de junho. Cabe ressaltar que a taxa de incidência é um indicador amplamente utilizado nos estudos da área da saúde e vigilância epidemiológica por demonstrar a intensidade da ocorrência de determinada doença e por permitir comparações entre a frequência e/ou probabilidade de ocorrência de novos casos da doença na população (BRASIL, 1998).

Nesse contexto, até 21 de junho de 2020, no Estado da Bahia, o coeficiente de incidência foi de 311,16 por 100.000 habitantes, valor abaixo da média nacional para o mesmo período que segundo dados do Ministério da Saúde (BRASIL, 2020) estava em cerca de 508 casos por 100 mil habitantes. Neste cenário o Estado da Bahia apresentava a menor taxa de incidência dentre os estados da Região Nordeste, tendo em vista que o Estado do Ceará na mesma data liderava com incidência de 1.009 por 100 mil hab. Já comparado com outros estados de outras regiões, evidencia-se que a Bahia apresentava incidência média/alta. Tendo em vista que estados da Região Sul e Centro Oeste apresentavam valores menores, a exemplo do Estado do Paraná que demonstrava incidência de 119,5 para o mesmo período, ao passo que estados da região nordeste e norte apresentavam 
incidência superiores, a exemplo do Estado do Amapá que apresentava incidência de 2.550,9 para cada 100 mil habitantes (BRASIL, 2020).

Ao analisarmos os valores de incidência nos municípios baianos em 21 de junho, observa-se que trinta e seis municípios apresentavam taxas de incidência acima da média estadual para a mesma data, com destaque para os municípios de Ipiaú, Uruçuca, Itajuípe, Gandu e São José da Vitória que apresentavam alarmantes taxas de incidência superiores a 1.000 casos por 100.000 habitantes. (SESAB, 2020). Conforme exposto na Figura 4, estes municípios se localizam às margens de entroncamentos rodoviários e/ou da rodovia federal BR-101, fato que novamente atesta a influência das estruturas de transporte na disseminação e interiorização do coronavírus no Estado da Bahia (AGUIAR, 2020).

Nesta mesma data, trezentos e vinte e dois municípios apresentavam taxa de incidência abaixo da média estadual de 311 casos por 100.000 habitantes. E cinquenta e oito municípios apresentavam taxa de incidência inexistente, igual a zero. Dentre os municípios com baixas taxas de incidência, dáse destaque para a Região Centro-Oeste do estado, notadamente uma região de menor densidade demográfica e pautada no distanciamento dos grandes eixos econômicos e de transporte, tais como a rodovia federal BR-101.

Figura 5 - Mapa da taxa de incidência da COVID-19 no Estado da Bahia, dia 21/06/2020

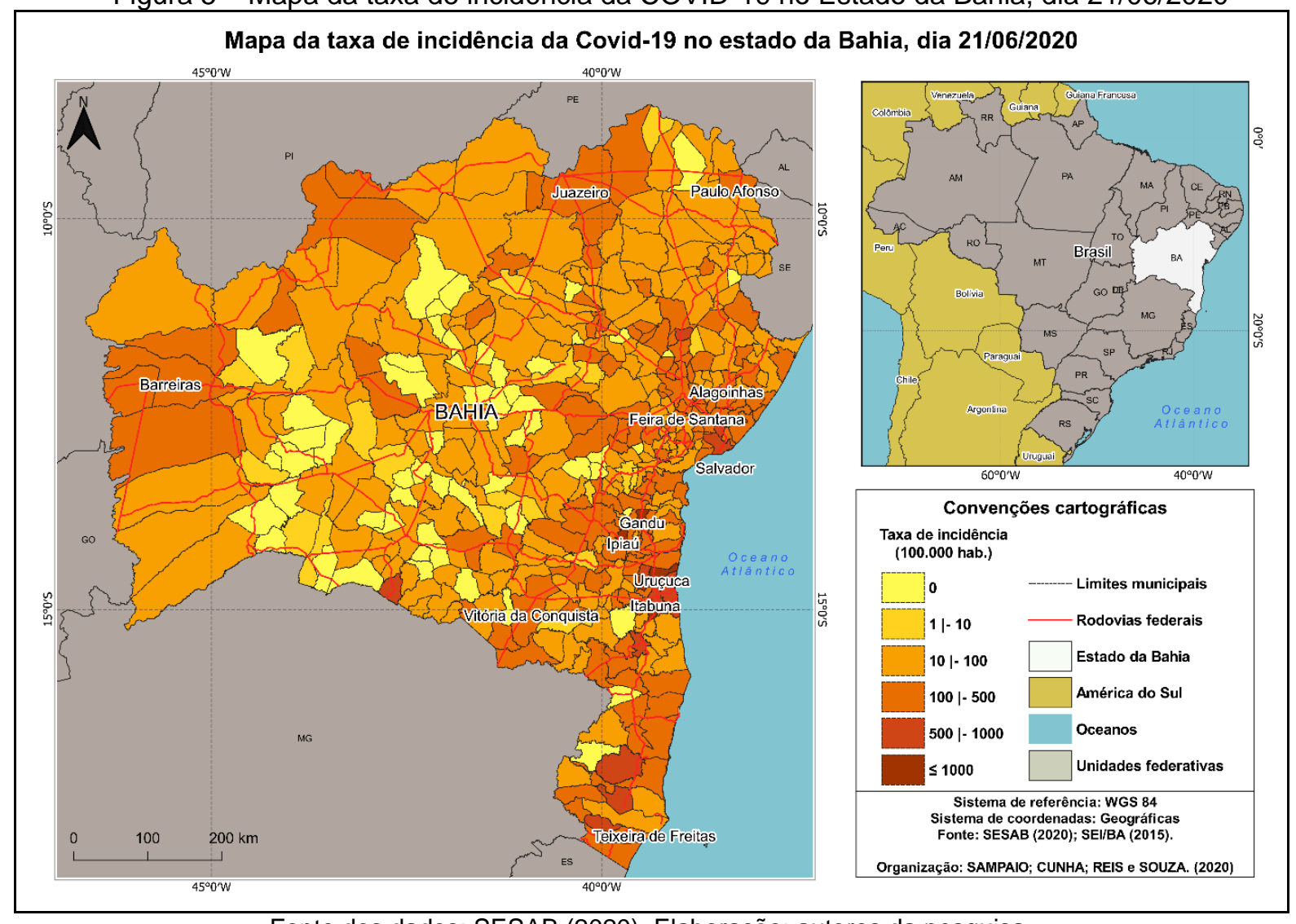

Fonte dos dados: SESAB (2020). Elaboração: autores da pesquisa.

No que se refere a espacialização dos óbitos registrados que tiveram como causa a COVID-19, de acordo com a Figura 6 foram confirmados até o dia 21 de junho de 2020 o total de 1.391 óbitos de contaminados no Estado da Bahia, representando uma letalidade aproximada em $3,01 \%$ dos contaminados (SESAB, 2020). Cabe destacar que diversos estudos realizados nos estados brasileiros indicam uma subnotificação dos casos confirmados e dos óbitos, a exemplo do estudo de Nogueira et al. (2020) que evidenciaram no Estado de Santa Catarina, uma subnotificação de óbitos relacionados a COVID-19 em cerca de $278 \%$.

Neste aspecto, dentre os óbitos registrados no Estado da Bahia, cerca de $54,85 \%$ incidiram no sexo masculino e $45,15 \%$ no sexo feminino, ao passo que cerca de $71 \%$ dos óbitos registrados nesta data apresentavam idade igual ou superior a sessenta anos (SESAB, 2020), fato que destaca a 
necessidade de identificação e mapeamento de municípios com maior concentração de população idosa, tendo em vista o necessário planejamento e gestão dos instrumentos e equipamentos de saúde.

Entre os municípios com maior registro de óbitos, destaca-se a capital Salvador (904), seguida pelos municípios de Itabuna (51), Ilhéus (39), Feira de Santana (31) e Lauro de Freitas (27), os quais novamente apresentam elevada correlação espacial com a distribuição de rodovias estaduais e federais, o que denota a inter-relação entre os sistemas fixos e fluxos, pré-requisito para a tomada de decisão frente a determinação de medidas restritivas de isolamento associadas ao estudo e entendimento do comportamento da doença do estado, ao planejamento de gestão de saúde, e a necessidade de avaliação visando a construção de novos equipamentos hospitalares, com destaques para novos leitos de terapia intensiva.

Figura 6 - Mapa de óbitos por COVID-19 no Estado da Bahia, até dia 21/06/2020

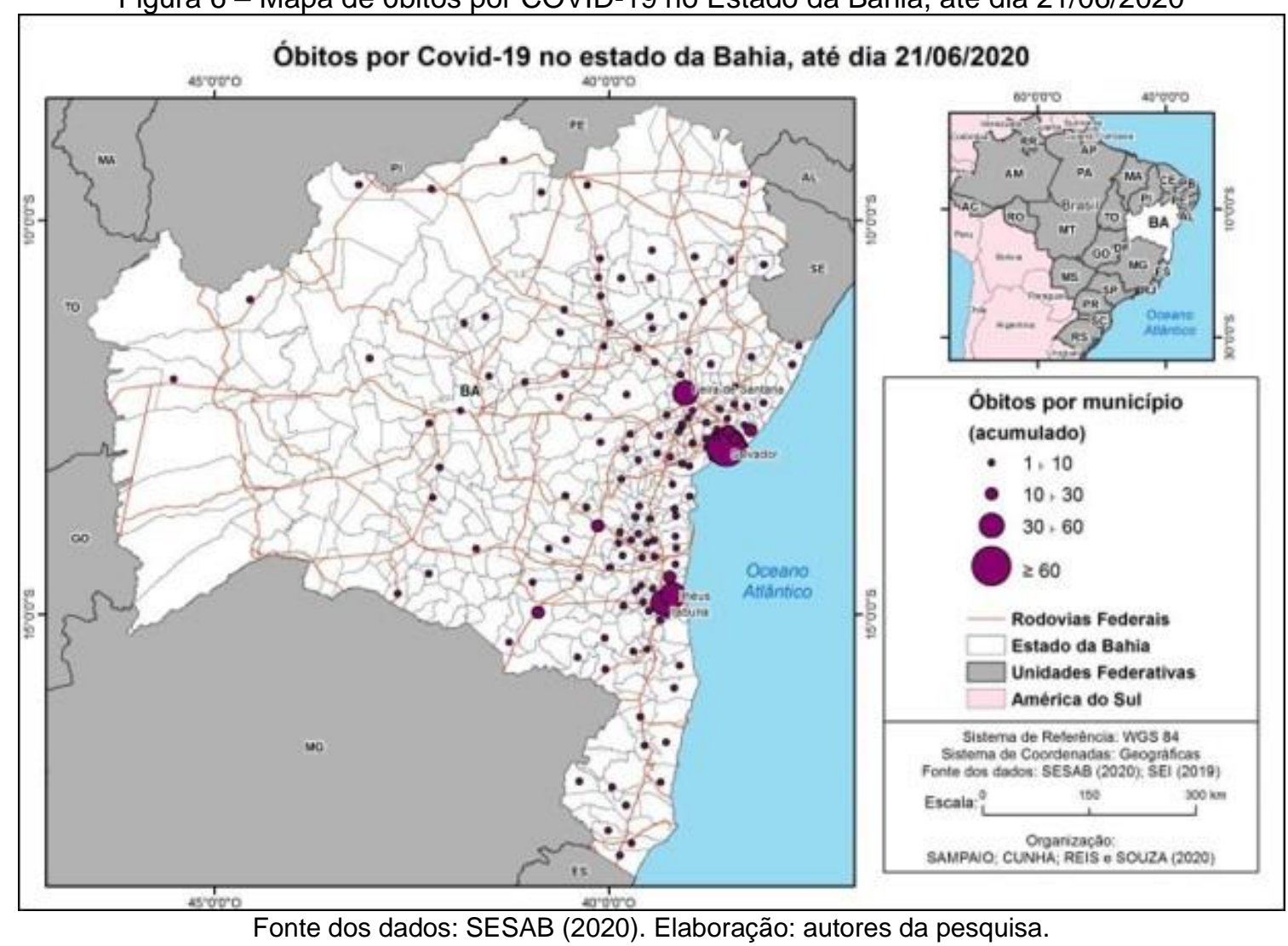

No tocante ao planejamento e gestão do sistema de saúde frente ao enfrentamento da pandemia da COVID-19, a Figura 7 indica a distribuição por município da população com idade superior a 60 anos e ilustra a distribuição espacial dos leitos de UTI no estado até o dia 21 de junho de 2020. Com relação à distribuição da população com mais de 60 anos, segundo dados disponibilizados pelo IBGE (2020), em onze municípios do estado, a população com idade superior a 60 anos representa mais de $16 \%$ da população municipal. Esta circunstância deve ser levada em conta no planejamento hospitalar e de saúde, tendo em vista que até 21 de junho cerca de $71,4 \%$ dos óbitos registrados no estado abrangiam indivíduos com idade superior a 60 anos, perfil etário tido como grupo de risco no enfrentamento da atual pandemia.

Desta forma, os municípios de Abaíra, Jussiape, Brotas de Macaúbas, Tremedal, Maetinga, Caraíbas, Rio de Contas, Capela do Alto Alegre, Mortugaba, Elísio Medrado e Jacaraci devem ser incluídos no planejamento estratégico regional de saúde e enfrentamento da pandemia, tendo em vista que são municípios com uma quantidade de habitantes reduzida, os quais não dispõem de equipamentos hospitalares com UTI's e se encontram distantes da Região Metropolitana, onde está a maior parte dos leitos (IBGE, 2020).

Ainda na discussão etária, outros cento e noventa e um municípios do Estado da Bahia apresentam de 12 a 16\% de população total com mais de 60 anos de idade. Este conjunto de municípios, representa cerca de $45,80 \%$ do território baiano e se distribui pelas regiões Centro Sul, Centro e

DOI: http://dx.doi.org/10.14393/Hygeia17058324 Hygeia $\quad$ v.17 $\quad$ p. 198-215, 2021 página 208 
Centro Norte do estado. Em sua grande maioria também não dispõem de unidades de terapia intensiva, mas se localizam relativamente próximos de unidades regionais de saúde que dispõem de um número reduzido de leitos de UTI, fato que reafirma a necessidade do aprimoramento do planejamento estratégico entre estes municípios e os centros regionais, estipulando unidades hospitalares preferenciais para o recebimento dos pacientes externos e os protocolos de agendamento e encaminhamento.

Figura 7 - Mapa da distribuição dos leitos de Unidade de Terapia Intensiva (UTI) e da população acima dos 60 anos de idade no Estado da Bahia,

2020

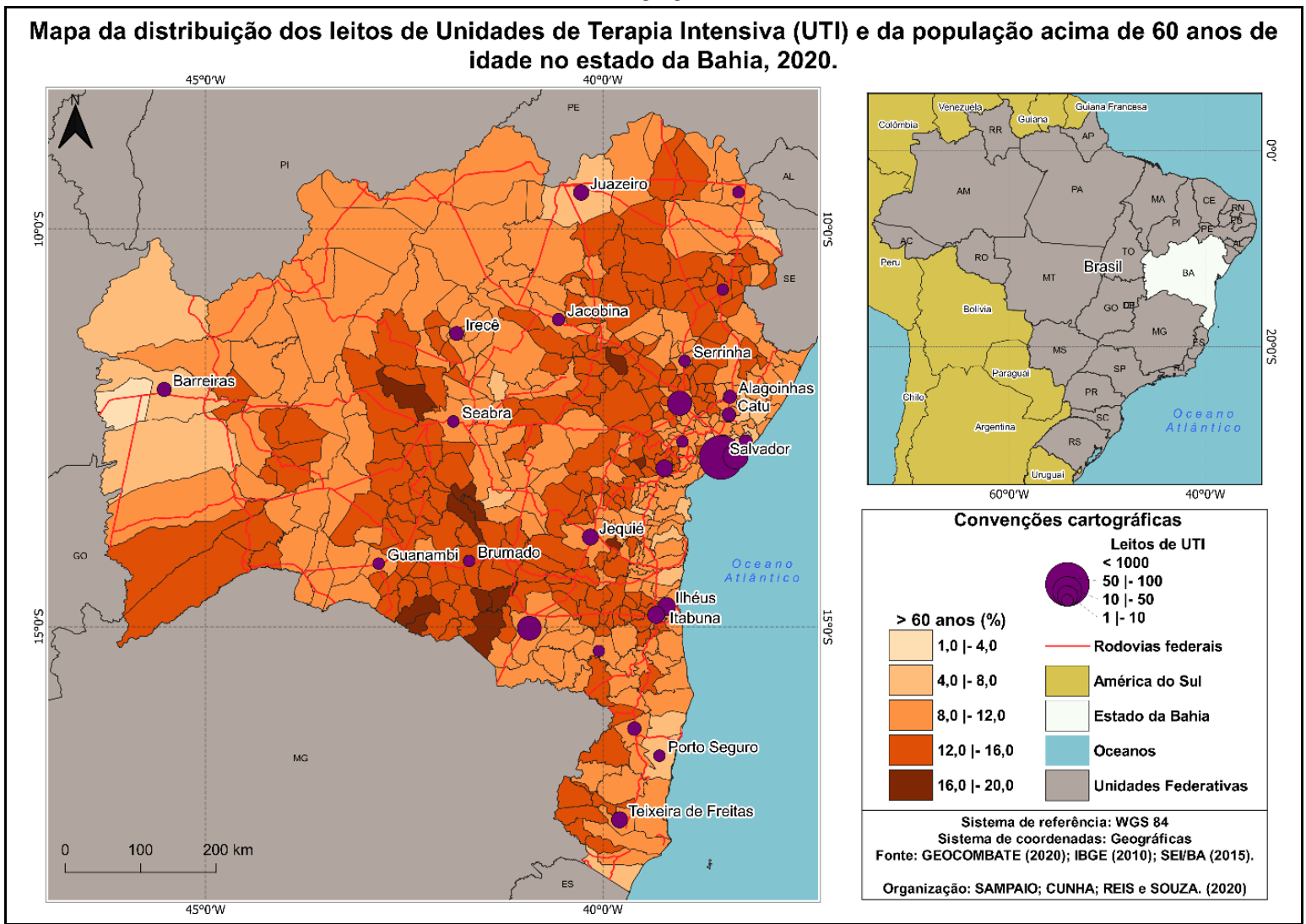

Fonte dos dados: GEOCOMBATE (2020); IBGE (2010). Elaboração: autores da pesquisa.

Em referência à distribuição de unidades de terapia intensiva, conforme ilustrado na Figura 7 , em junho de 2020 a Bahia contava com 1.930 leitos de UTI, ao passo que a Região Metropolitana de Salvador congregava cerca de 1.254 leitos, o que denota a concentração de $64,97 \%$ de todos os leitos de UTI dispostos no estado (GEOCOMBATE, 2020). Ressalta-se que a análise da distribuição dos leitos de UTI foi realizada a partir da base de dados distribuídas pelo grupo Geocombate COVID19 Bahia, pertencente à Universidade Federal da Bahia (UFBA). Entretanto, em decorrência da rapidez da propagação dos casos e da contínua criação de hospitais de campanha e leitos emergenciais, estes números podem apresentar certas desatualizações, inerentes às análises deste cunho neste período.

Seguindo a análise, constata-se que, até junho de 2020 , trezentos e noventa municípios do estado não detinham de leitos de UTI, ou seja, cerca de $93,52 \%$ dos municípios do estado não detinham de leitos necessários para o tratamento e acompanhamento dos agravamentos gerados pela infecção da COVID-19. Nesse âmbito, conforme indicado pela Tabela 1, dos vinte e sete territórios de identidade que regionalizam o Estado da Bahia e instrumentalizam a ocorrência de diversas políticas públicas, oito não constam com unidades de terapia intensiva. Tal dado assusta e demonstra a extrema necessidade de um planejamento estratégico voltado para o fortalecimento da atenção terciária nos núcleos de saúde dispostos nos territórios de identidade, que já detêm de centros regionais e estruturas associadas (GEOCOMBATE, 2020). 
Análise espacial dos casos da COVID-19 e leitos de terapia intensiva no estado da Bahia-Brasil
Sarah Andrade Sampaio

Gabriel Carneiro Silva Cunha

Felipe de Souza Reis

Sirius Oliveira Souza

Tabela 1 - Distribuição de Leitos de UTI por Território de Identidade no Estado da Bahia

\begin{tabular}{|c|c|c|}
\hline Território de Identidade & Quantidade de Leitos & Municípios com leitos de UTI \\
\hline Metropolitano de Salvador & 1254 & Salvador*; Candeias; Camaçari e Lauro de Freitas* \\
\hline Portal do Sertão & 124 & Feira de Santana* \\
\hline Território de Identidade & Quantidade de Leitos & Municípios com leitos de UTI (Cont.) \\
\hline Sudoeste Baiano & 119 & Vitória da Conquista* \\
\hline Litoral Sul & 97 & Ilhéus e Itabuna* \\
\hline Recôncavo & 51 & São Félix e Santo Antônio de Jesus \\
\hline Extremo Sul & 37 & Teixeira de Freitas* \\
\hline Médio Rio de Contas & 36 & Jequié \\
\hline Sertão do São Francisco & 31 & Juazeiro* \\
\hline Costa do Descobrimento & 29 & Eunápolis e Porto Seguro \\
\hline Litoral Norte e Agreste Baiano & 28 & Alagoinhas e Catu* \\
\hline Bacia do Rio Grande & 22 & Barreiras* $^{*}$ \\
\hline Irecê & 21 & Irecê $\hat{e}^{*}$ \\
\hline Sertão Produtivo & 20 & Brumado e Guanambi \\
\hline Piemonte da Diamantina & 13 & Jacobina* $^{*}$ \\
\hline Chapada Diamantina & 10 & Seabra \\
\hline Itaparica & 10 & Paulo Afonso* \\
\hline Sisal & 10 & Serrinha* \\
\hline Médio Sudoeste da Bahia & 9 & Itapetinga \\
\hline Semiárido Nordeste II & 9 & Ribeira do Pombal ${ }^{*}$ \\
\hline Bacia do Jacuípe & 0 & Não possuem \\
\hline Bacia do Paramirim & 0 & Não possuem \\
\hline Bacia do Rio Corrente & 0 & Não possuem \\
\hline Baixo Sul & 0 & Não possuem \\
\hline Piemonte do Paraguaçu & 0 & Não possuem \\
\hline Piemonte Norte do Itapicuru & 0 & Não possuem \\
\hline Vale do Jiquiriçá & 0 & Não possuem \\
\hline Velho Chico & 0 & Não possuem \\
\hline Total & 1.930 & \\
\hline
\end{tabular}

Observação: Os municípios sinalizados $\left(^{*}\right)$ representam municípios que em junho de 2020 já haviam recebido leitos adicionais
de UTI voltados ao tratamento da COVID-19. Fonte dos dados: GEOCOMBATE (2020). Organização: autores da pesquisa. 
A exemplo pode-se citar o Território de Identidade do Piemonte Norte do Itapicuru que é composto por nove municípios: Andorinha, Antônio Gonçalves, Caldeirão Grande, Campo Formoso, Filadélfia, Jaguarari, Pindobaçu, Ponto Novo e Senhor do Bonfim, que juntos conglomeram cerca de 270 mil habitantes (IBGE, 2019) e não possui leitos de UTI, impulsionando esses municípios a enviarem contaminados em estágios graves para outros territórios de identidade, onerando os órgãos públicos e sobrecarregando o sistema de saúde dos municípios detentores de leitos de terapia intensiva.

Tendo em vista o exposto, o uso da análise espacial aplicada a dados sobre a COVID-19, a exemplo do número de casos, de óbitos e quanto à disponibilidade dos leitos hospitalares em cada município, permite o entendimento dos possíveis eixos de disseminação da pandemia no contexto do território baiano, ao passo que registra também a distribuição de uma certa fatia da população mais vulnerável ao vírus e a distribuição das estruturas de atendimento aos casos graves.

No contexto estudado, foi possível identificar dois principais circuitos espaciais de difusão da COVID19 na Bahia, que foram a rodovia BR-101 e a rodovia BR-116, ambas são rodovias longitudinais federais com elevado fluxo de circulação de pessoas e mercadorias, que atravessam diversos estados brasileiros e se destacam enquanto principais eixos rodoviários do país. Para o Estado da Bahia a circulação de veículos e transportes coletivos por essas rodovias possibilitou a propagação e disseminação do vírus e, por consequência, se relacionou com a distribuição dos óbitos, dentro do período estudado.

Desta forma, a adoção de medidas de restrição de circulação de pessoas, mesmo que de forma heterogênea e flexível como ocorreu no Estado da Bahia, demonstra ser um importante alternativa para redução do número de infectados e controle emergencial da disseminação do vírus. Tais decisões devem ser acompanhadas de planejamentos estratégicos para os equipamentos de saúde e para os agentes econômicos/sociais envolvidos. À vista disso, a análise espacial se fortalece enquanto um importante aparato no monitoramento da evolução da COVID-19 e na consolidação de estratégias e medidas de controle, prevenção e enfrentamento.

\section{CONSIDERAÇÕES FINAIS}

Os procedimentos utilizados neste trabalho, pautados em rotinas de SIG, permitiram a discussão de informações relevantes perante a atual crise pandêmica. Sabe-se que o surgimento de uma pandemia sempre está associado a incertezas quanto às ações de combate ao desenvolvimento da doença, às aplicações de políticas de saúde pública, assim como as previsões espaço-temporais de desenvolvimento da doença, além de oferecer riscos à saúde coletiva de forma ininterrupta. Tendo em vista tal potencialidade, esse trabalho se pautou na espacialização dos dados sobre a distribuição da COVID-19 no território baiano, relacionados à distribuição espacial dos leitos de UTI e da população com idade superior a 60 anos.

Quanto a distribuição dos casos da COVID-19 no Estado da Bahia, o coeficiente de incidência foi, em 21 de junho de 2020 , de 311,16 por 100.000 habitantes, sendo que trinta e seis municípios apresentavam taxas de incidência acima da média estadual para a mesma data, com destaque para os municípios de Ipiaú, Uruçuca, Itajuípe, Gandu e São José da Vitória que apresentavam alarmantes taxas de incidência superiores a 1.000 casos por 100.000 habitantes (SESAB, 2020).

Quanto à distribuição dos leitos de Unidade de Terapia Intensiva, e tendo em vista que este estudo pautou-se na análise da população idosa - acima de 60 anos, verificou-se que a Bahia contava com 1.930 leitos de UTI, ao passo que a Região Metropolitana de Salvador congregava cerca de 1.254 leitos, enquanto a população considerada mais vulnerável e, portanto, com a maior probabilidade de necessitar de UTIs, cuja faixa etária é de mais de 60 anos, concentra-se na região centro sul e centro leste do estado. Isto posto, cabe ressaltar que no dia 21 de junho cerca de $71,4 \%$ dos óbitos registrados no estado abrangiam indivíduos com idade superior a 60 anos. Além disso, foi possível constatar que até junho de 2020 , trezentos e noventa municípios do estado não detinham de leitos de UTI, ou seja, cerca de $93,52 \%$ do território baiano (SESAB, 2020).

Este estudo fornece alguns indicativos dos principais circuitos de dispersão do vírus no período analisado no Estado da Bahia, os quais podem ser levados em consideração frente a futuras 
ocorrências de pandemias equivalentes. Ao passo que fortalece a importância de planejamentos integrados em saúde, que articulem a identificação e monitoramento de pontos e rotas de dispersão do vírus concomitantemente à intervenção controlada de diagnósticos, tratamentos e implantação de medidas restritivas. Tal articulação tem apresentado bons resultados na mitigação/contenção de processos pandêmicos.

É importante assinalar que esta breve análise trata de modo preliminar o processo de disseminação da COVID-19 no Estado da Bahia, levando em conta que em junho de 2020 ainda não se havia chegado à fase aguda da contaminação. Cabe também destacar que este trabalho optou por analisar apenas a variável idade, indicada na literatura contemporânea enquanto principal variável relacionada a agravamentos e óbitos de COVID-19 (MACIEL et al., 2020; LIU et al., 2020). Entretanto, as causas e consequências da disseminação espacial da COVID-19 são complexas, fato que desperta a necessidade da continuidade de análises e pesquisas. Portanto, reitera-se a necessidade de maiores estudos voltados a distribuição do vírus e de estudos que tratem outras variáveis relacionadas aos fatores de risco à doença, com destaque para o fator renda, que é determinante no comportamento $e$ nível de isolamento social dos indivíduos (BEZERRA et al., 2020).

Desta forma, é evidente a exigência de estudos mais detalhados que versem sobre a análise espacial da COVID-19 no Estado da Bahia, visto o desafio do planejamento em saúde, a criticidade na distribuição de equipamentos e, sobretudo, a vulnerabilidade social de grande parcela da população baiana. Ao final, reitera-se a importância de políticas públicas que permitam a manutenção da renda das famílias, do isolamento social dos indivíduos e a ampliação dos leitos disponíveis no SUS, enquanto alternativas viáveis para o enfrentamento e mitigação da pandemia.

\section{REFERÊNCIAS}

ARCHELA, R. S.; THÉRY, H. Orientação metodológica para construção e leitura de mapas temáticos. Confins [Online], v. 3, p. 22, 2008. https://doi.org/10.4000/confins.3483

BARBOSA, I. R. et al. Análise da distribuição espacial da tuberculose na região Nordeste do Brasil, 2005-2010. Epidemiologia e Serviços de Saúde, v. 22, n. 4, p. 687-695, 2013. https://doi.org/10.5123/S1679-49742013000400015

Incidência e mortalidade por COVID-19 na população idosa brasileira e sua relação com indicadores contextuais: um estudo ecológico. Revista Brasileira de Geriatria e Gerontologia, v. 23, n. 1, 2020.

BEZERRA, A.C.V.; SILVA, C. E. M.; SOARES, F. R. G.; SILVA, J. A. M. Fatores associados ao comportamento da população durante o isolamento social na pandemia de COVID-19. Ciência \& Saúde Coletiva, v. 25, p. 2411-2421, 2020. Disponível em: <https://doi.org/10.1590/141381232020256.1.10792020>. Acesso em 12 fev. 2021. https://doi.org/10.1590/141381232020256.1.10792020

BRASIL. Ministério da Saúde. Rede Intergeracional das Informações para a Saúde - RIPSA: Taxa de incidência de doenças transmissíveis. 1998. Disponível em: <http://tabnet.datasus.gov.br/cgi/idb199 8/fqd02_2.htm>. Acesso em: 25 jun. 2020.

Secretaria de Vigilância em Saúde. Boletim Epidemiológico Especial: Doença pelo Corona Vírus Covid-19. 2020. Disponível em: <http://saude.gov.br/images/pdf/2020/June/25/Boletimepidemiologico-COVID-19-2.pdf>. Acesso em: 23 jun. 2020.

CÂMARA, G.; CARVALHO, M. S. Análise espacial de eventos. 2004. In: DRUCK, S.; CARVALHO, M. S.; CÂMARA, G.; MONTEIRO, A. M. V. (Org.). Análise espacial de dados geográficos. Brasília: Embrapa, 2004. Disponível em: < http://www.dpi.inpe.br/gilberto/livro/analise/>. Acesso em: 27 jun. 2020.

CARDOSO, P. V.; SEABRA, V. da S.; BASTOS, I. B.; COSTA, E. de C. P. A importância da análise espacial para tomada de decisão: um olhar sobre a pandemia de Covid-19. Revista Tamoios, v. 16,
n. $\quad 1$
p. $\quad 125-137$.
2020.
Disponível
em:
$<$ https://www.e-

DOI: http://dx.doi.org/10.14393/Hygeia17058324 $\quad$ Hygeia $\quad$ v.17 $\quad$ p. 198-215, 2021 página 212


publicacoes.uerj.br/index.php/tamoios/article/view/50440>. Acesso: 19 jun. 2020. https://doi.org/10.12957/tamoios.2020.50440

CAVALCANTE, J. R.; ABREU, A. de J. L. COVID-19 no município do Rio de Janeiro: análise espacial da ocorrência dos primeiros casos e óbitos confirmados. Epidemiologia e Serviços de Saúde, v. 29, jun. 2020. Disponível em: < https://www.scielo.br/scielo.php?script=sci_arttext\&pid=S223796222020000300302>. Acesso em: 13 jun. 2020. https://doi.org/10.5123/S1679-49742020000300007

CORREIA, P. de P. Manual de Geopolítica e Geoestratégia, Vol. Il-Análise Geoestratégica de um Mundo em Conflito. Coimbra: Quarteto, 2004.

DIAS, M. C. et al. The challenges for labour market policy during the Covid-19 pandemic. Fiscal Studies, v. 41, n. 2, p. 371-382, 2020. https://doi.org/10.1111/1475-5890.12233

MEDIDAS já anunciadas pelo governo da Bahia em combate ao coronavírus no estado. G1, 2020. Disponível em: <https://g1.globo.com/ba/bahia/noticia/2020/03/19/governo-da-bahia-anunciamedidas-de-combate-ao-coronavirus-no-estado.ghtml>. Acesso: 21 jun 2020.

GEOCOMBATE. Portal Geocombate Covid-19 BA. 2020. Disponível em: $<$ https://sites.google.com/view/geocombatecovid19ba/dados-e-c\%C3\%B3digos?authuser=0>. Acesso em: 29 de jun. 2020.

GUERRA, O. F. Bahia: liderança econômica regional e desigualdade social. Bahia Análise \& Dados, v. 27, n. 2, p. 55-85, 2018.

GUERRA, O. F.; TEIXEIRA, F. L. C. 50 anos de industrialização baiana: do enigma a uma dinâmica exógena e espasmódica. Bahia Análise \& Dados Salvador, v. 10, n. 1, 2000.

GUERRA, O. F; GONZALEZ, P. S. H. Crescimento econômico e desigualdade social na Bahia. Conselho Regional de Economia da Bahia - CORECON-BA, 2013. Disponível em: <http://www.corecon-ba.org.br/wp-content/uploads/2013/09/Crescimento-Econ\%C3\%B4mico-e-

Desigualdade-Social-na-Bahia.pdf>. Acesso em: 10 jul. 2020.

INSTITUTO BRASILEIRO DE GEOGRAFIA E ESTATÍSTICA - IBGE. Pesquisa Nacional por Amostra de Domicílios - $\quad$ PNAD/Covid19. 2019. Disponível em:<https://covid19.ibge.gov.br/>. Acesso em: 22 jun. 2020. 2020.

Portal COVID-19, 2020. Disponível em: <https://covid19.ibge.gov.br/>. Acesso em: 20 jun.

Cidades e estados do Brasil. 2019. Disponível em: <https://cidades.ibge.gov.br/>. Acesso em: 18 jun. 2020.

KANG, D. CHOI, H. KIM, J. CHOI, J. et al. Spatial epidemic dynamics of the COVID-19 outbreak in China. International Journal of Infectious Diseases.03 abril de 2020. Disponível em: <https://www.ijidonline.com/article/S1201-9712(20)30209-5/abstract>. Acesso em 12 jun. 2020.

LAIA, C.; SHIH, W; KOC, W.; TANG, H;. HSUEH, P. Severe acute respiratory syndrome coronavirus 2 (SARS-CoV-2) and corona virus disease-2019 (COVID-19): the epidemic and the challenges. International Journal of Antimicrobial Agents, v. 55, n. 3, mar. 2020. Disponível em: < https://www.sciencedirect.com/science/article/pii/S0924857920300674>. Acesso em: 20 jun. 2020. https://doi.org/10.1016/j.ijantimicag.2020.105924

LIU, K. et al. Clinical features of COVID-19 in elderly patients: A comparison withyoung and middleaged patients. Journal of Infection; 2020. doi:10.1016/j.jinf.2020.03.005. https://doi.org/10.1016/i.jinf.2020.03.005

MACIEL, E. L. et al. Fatores associados ao óbito hospitalar por COVID-19 no Espírito Santo, 2020. Epidemiologia e Serviços de Saúde [online]. v. 29, n. 4. Disponível em: <https://doi.org/10.1590/S1679-49742020000400022>. Acesso em: 19 out. 2020 . https://doi.org/10.1590/s1679-49742020000400022

MAGALHÃES, S. C. M.; SANTOS, F. DE O.; LIMA, S. DO C.; FONSECA, E. DA S. Situação Epidemiológica da transmissão da Covid-19 no Norte de Minas Gerais, Brasil. Hygeia - Revista Brasileira de Geografia Médica e da Saúde, p. 80 - 87, 18 jun. 2020. https://doi.org/10.14393/Hygeia0054629 
MARTINUCI, O. DA S.; LIMA, V.; MARIA E.; ÂNGELA; C. M. O. GROCHOSKI F. M.; CRISTINA R.; K.; MILENE C., L.; BALIEIRO C. R.; BLAUDT L. S. R.; SILVA, H. S. Dispersão da Covid-19 no Estado do Paraná. Hygeia - Revista Brasileira de Geografia Médica e da Saúde, p. 251 - 262, 20 jun. 2020. https://doi.org/10.14393/Hygeia0054619

MATSUMOTO, P. S. S.; TENÓRIO CREPALDI, M.; AVANZI JÚNIOR, P. S.; OLIVEIRA, M. B.; DE REGALA, R. M. S.; ROSSEAL, T. V.; LIMA, J. P. C. Mapeamento de Covid-19 e isolamento social: ferramentas de monitoramento e vigilância em Saúde Pública. Hygeia - Revista Brasileira de Geografia Médica e da Saúde, p. 298 - 311, 20 jun. 2020. https://doi.org/10.14393/Hygeia0054553

MURUGESAN, B.; KARUPPANNAN, S.; MENGISTIE, A. T.; RANGANATHAN, M.; GOPALAKRISHNAN, G. Distribution and Trend Analysis of COVID-19 in India: Geospatial Approach. Journal of Geographical Studies, v. 4, n. 1, p. 1-9, 2020. https://doi.org/10.21523/gci5.20040101

NOGUEIRA, A. L.; NOGUEIRA, L.; ZIB ETTI, A. Estimativa da Subnotificação de Casos da Covid -19 no Estado de Santa Catarina. UFSC, 2020.

ORGANIZAÇÃO PAN-AMERICANA DA SAÚDE - OPAS. Indicadores de Saúde: Elementos conceituais e práticos. 2020a. Disponível em: <https://www.paho.org/hq/index.php?option=com _content\&view =article\&id=14402:health-indicators-conceptual-and-operational-considerationssection-2\&ltemid=0\&s howall=1\&lang=pt>. Acesso em 5 de jul. 2020.

em:

Folha informativa - COVID-19 (doença causada pelo novo coronavírus). 2020b. Disponível $\mathrm{n}=$ com_content\&view=article\&id=6101 :covid19\&ltemid=875>. Acesso em 5 de jul. 2020 .

PEDROSA, N. L.; ALBUQUERQUE, N. L. S. de. Análise Espacial dos Casos de COVID-19 e leitos de terapia intensiva no estado do Ceará, Brasil. Ciência \& Saúde Coletiva, v. 25, p. 2461-2468, 2020. Disponível em: < https://www.scielo.br/scielo.php?script=sci_abstract\&pid=S1413$81232020006702461 \& \operatorname{lng}=$ pt\&nrm=isso>. Acesso em: 28 jun. 2020. https://doi.org/10.1590/1413$\underline{81232020256.1 .10952020}$

RACHE, B.; ROCHA, R.; NUNES, L.; SPINOLA, P.; MALIK, A. M.; MASSUDA, A. Necessidades de infraestrutura do SUS em preparo à covid-19: leitos de UTI, respiradores e ocupação hospitalar. Nota Técnica n.3. IEPS: São Paulo. Disponível em: <http://www.epsjv.fiocruz.br/sites/default/files/files/NT3\%20vFinal.pdf >. Acesso em: 12 jun. 2020.

REN, L. L.; WANG, Y. M.; WU, Z. Q.; XIANG, Z. C.; GUO, L.; XU, T.; LI, H. Identification of a novel coronavirus causing severe pneumonia in human: a descriptive study. Chinese medical journal, 2020. Disponível em: <https://www.ncbi.nlm.nih.gov/pmc/articles/PMC7147275/>. Acesso em: 18 jun. 2020.

REZENDE, J. M. de. Epidemia, endemia, pandemia, epidemiologia. Revista de Patologia Tropical/Journal of Tropical Pathology, v. 27, n. 1, 1998. Disponível em: $<$ https://www.revistas.ufg.br/iptsp/article/download/17199/10371??journal=iptsp>. Acesso em: 02 jul. 2020.

SANTOS, V. R. D., YOKOO, E. M., SOUZA-SANTOS, R., \& ATANAKA-SANTOS, M. Fatores socioambientais associados à distribuição espacial de malária no assentamento Vale do Amanhecer, Município de Juruena, Estado de Mato Grosso, 2005. Revista da Sociedade Brasileira de Medicina Tropical, v. 42, n. 1, p. 47-53, 2009. https://doi.org/10.1590/S0037-86822009000100010

SECRETARIA DE SAÚDE DO ESTADO DA BAHIA - SESAB. Boletins Epidemiológicos do Covid19. 2020. Disponível em: <http://www.saude.ba.gov.br/temasdesaude/coronavirus/notas-tecnicas-eboletins-epidemiologicos-covid-19/>. Acesso em: 21 jun. 2020.

SILVA, R. J. et al. Análise espacial sobre a dispersão da covid-19 no Estado da Bahia. Scielo. Nota Técnica. 2020. https://doi.org/10.1590/SciELOPreprints.39

SIMIONATTO, S.; BARBOSA, M.; MARCHIORO, S. B. COVID-19 in Brazilian indigenous people: a new threat to old problems. Rev. Soc. Bras. Med. Trop., Uberaba, v. 53, 2020. Disponível em: $<$ http://www.scielo.br/scielo.php?script=sci_arttext\&pid=S0037-

86822020000100915\&lng=en\&nrm=iso>. Acesso: 25 nov. 2020. https://doi.org/10.1590/0037-8682$\underline{0476-2020}$ 
SOUZA, C.; FRANCA, A. G.; ROCHA, W. J. S. A. DA; LIMA, R. S. Distribuição Espacial da Endemia Hansênica em menores de 15 anos em Juazeiro - Bahia, entre 2003 e 2012. Hygeia - Revista Brasileira de Geografia Médica e da Saúde, v. 10, n. 19, p. 35 - 49, 17 dez. 2014.

SOUZA, N. P. de; SILVA, E. M. G. C.; TEIXEIRA, M. D.; LEITE, L. R. Aplicação do Estimador de Densidade Kernel em Unidades de Conservação na Bacia do Rio São Francisco para análise de focos de desmatamento e focos de calor. INSS: 4958-4965. 2013. In: Anais XVI Simpósio Brasileiro de Sensoriamento Remoto - SBSR, Foz do Iguaçu, PR, Brasil, 13 a 18 de abril de 2013, INPE.

SUPERINTENDÊNCIA DE ESTUDOS ECONÔMICOS E SOCIAIS DA BAHIA - SEI. Cartografia de referência: Base de dados. Salvador: SEI, 2015.

Produto Interno Bruto e Estudos Correlatos. Salvador: SEI, 2017. Disponível em: $<$ http://www.sei.ba.gov. Acesso em: 11 jul. 2020.

TEIXEIRA, S. H. DE O.; SOUZA, A. L. DE. Análise da Distribuição Geográfica de Covid-19 na Mesorregião Sul/Sudoeste de Minas Gerais. Hygeia - Revista Brasileira de Geografia Médica e da Saúde, p. 407 - 416, 25 jun. 2020. https://doi.org/10.14393/Hygeia0054632

ZHAO, S.; ZHUANG, Z.; RAN, J.; LIN, J.; YANG, G.; YANG, L. The association between domestic train transportation and novel coronavirus (2019-nCoV) outbreak in China from 2019 to 2020: a datadriven correlational report Travel. Med Infect Dis, p. 101568 - 101016. 2020. Disponível em: $<$ https://www.researchgate.net/publication/338918197_The_association_between_domestic_train_tra nsportation_and_novel_coronavirus_outbreak_in_China_from_2019_to_2020_A_datadriven_correlational_report>. Acesso em: 12 jun. 2020. https://doi.org/10.1016/j.tmaid.2020.101568 